\title{
TEORÍA MARXISTA DEL ESTADO Y SUS USOS EN LA ANTROPOLOGÍA
}

\section{MATIAS CALDERÓN*}

\section{Introducción}

Desde inicios de la década del 2000 , el neoliberalismo se viene impugnando con fuerza en varios países de América del Sur. No solo ha existido un cuestionamiento retórico, sino que se han establecido gobiernos que sustentados en fuerzas sociales y políticas de distinto tipo, han llegado al poder estatal e impulsado -más allá de las diferencias y resultados- proyectos de su superación ${ }^{1}$. Lo cual implica no solo una disputa por el poder en la gestión del Estado, sino que conlleva una transformación de este y de sus articulaciones con la sociedad (Ouviña \& Thwaites, 2018).

Chile, a pesar de ser uno de los países donde el neoliberalismo se había profundizado a niveles máximos, con notorias consecuencias en la desigualdad y precarización de la vida de la población, no presentaba fuerzas sociales y políticas articuladas con un fin equivalente. No obstante la existencia de movilizaciones sectoriales y territoriales que cuestionaban los efectos del modelo, no se había configurado en una fuerza similar (Gaudichaud, 2015).

Sin entrar en los detalles de los acontecimientos y su complejidad, desde el 18 de octubre de 2019 en Chile, se experimenta un amplio proceso de movilización social contra la vida bajo el neoliberalismo. En un primer momento adquirió forma de lo que ha sido llamado como "estallido social", pero con el pasar de días, semanas y meses, se figura como una movilización social que cuestiona las bases del neoliberalismo (incluso ha obligado a la apertura de un proceso constituyente). En este contexto, el Ejecutivo ha desplegado abiertamente todas las herramientas del Estado, buscando el control y represión de los manifestantes para asegurar el sostenimiento de este orden y la desactivación de las movilizaciones. Las acciones violentas y masivas que ha impulsado el Estado, han conducido a que se hayan denunciado graves violaciones a los derechos humanos, constatadas en diversos informes de organismos nacionales e internacionales ${ }^{2}$. Junto con ello y, en gran medida, los principales medios de comunicación, han servido como dispositivos de difusión de discursos e imaginarios que buscan deslegitimar la movilización y sustentar el orden neoliberal.

En este escenario, cabe preguntarse cuál es el papel que podemos cumplir los científicos sociales en general y los antropólogos en particular. Creemos que hay dos frentes igualmente importantes. Por un lado, impulsar acciones políticas directas, por ejemplo, apoyo y participación en movilizaciones, asambleas, cabildos, hacer difusión, etc. Son aspectos fundamentales para el éxito del proceso. Por otro, quizás menos visible en el corto plazo, recuperar,

\footnotetext{
* Dr. (c) en Antropología. Programa de Doctorado en Antropología y Arqueología, Universidad Católica del Norte, San Pedro de Atacama, Chile. Correo-e: matias.calderon@alumnos.ucn.cl; mcalderonseguel@gmail.com
} 
elaborar y difundir perspectivas teóricas que puedan apoyar la reflexión crítica, la elaboración de propuestas y la práctica.

Este escrito forma parte del segundo tipo de aportes. La teoría marxista se ha dedicado a analizar el rol del Estado en el capitalismo y en las formaciones que presentan las clases sociales, es decir, que se configuran de forma estructuralmente desigual. Son herramientas teóricas relevantes de revisar en este momento, ya que actualmente está en disputa la forma que queremos darle al país, al Estado y su relación con la sociedad, para las décadas siguientes. Por ende, las reflexiones teóricas acá presentadas son un aporte para entender el comportamiento estatal y pensar en los caminos que deberían seguirse en un proyecto transformador. No obstante, en este documento, no se efectúan análisis de la coyuntura política concreta.

Esta revisión no tiene pretensiones de exhaustividad, sino que es una aproximación general a autores claves de la reflexión marxista sobre el Estado, a algunos de sus textos más importantes y al uso de estas orientaciones en la antropología social. No hay espacio para profundizar en los distintos planteamientos ni en las variaciones de los autores a lo largo de su vida. Es un preludio que invita a que quienes se sientan convocados/as puedan profundizarlos.

En lo que sigue, revisamos las tesis centrales de Marx y Engels, seguimos con Lenin y Gramsci para el marxismo de las primeras décadas del siglo XX, luego exploramos en el marxismo estructural de la segunda mitad del siglo $X X$, señalamos algunos acercamientos antropológicos al tema, y más adelante, exponemos algunas aproximaciones disciplinares desde Latinoamérica, para concluir con reflexiones finales.

\section{El Estado para Marx y Engels}

Las reflexiones de los fundadores del marxismo respecto del Estado las podemos encontrar en diversos textos y cartas, sin embargo, un libro fundamental es El origen de la familia, la propiedad privada y el Estado (Engels, s/f).

Los planteamientos que proponen abren focos de análisis en distintas direcciones sobre el origen y la naturaleza del Estado, nos interesa en este escrito dar cuenta del núcleo de sus ideas.

Corriendo el riesgo simplificador de toda síntesis, podemos señalar que el centro de sus concepciones es que el Estado como estructura política es una elaboración de la propia sociedad, la cual se configura una vez que (o a la vez que) la división social del trabajo ha avanzado hasta tal punto que ya se ha presentado la separación entre clases sociales que, por una parte, controlan los medios de producción sin efectuar trabajo inmediato en ellos y, por otro lado, los productores directos. A partir de las relaciones sociales de producción que conlleva esta división social, se ha presentado históricamente una apropiación del excedente del trabajo por parte de los controladores o propietarios de los medios de producción por sobre los productores directos; esto es una relación de explotación. Si bien la separación entre productores directos y medios de producción, como también los mecanismos de explotación, no son exclusividad del capitalismo, sí llegan a su condición máxima en este modo de producción mediante el establecimiento de la propiedad privada capitalista. La estructura de relaciones sociales que configura la propiedad privada, teniendo como base la explotación 
del trabajo, implican un conflicto (abierto o solapado) entre clases sociales, tanto por el excedente del trabajo como por los medios de producción (Marx \& Engels, 1999).

El Estado como estructura política producida y controlada por las clases dominantes, cumple un papel central en el mantenimiento y reproducción de la situación de explotación; sostiene el orden social procurando impedir que el conflicto de clases se exprese abiertamente. Para ello cuenta con agentes especializados (burocracia administrativa, punitiva y policial), la capacidad y el monopolio legal de la fuerza, la concentración del poder institucionalizado, entre otros mecanismos. De esta manera sostiene y reproduce las estructuras económico-sociales de una sociedad dividida que descansa en la explotación del trabajo. Es así como no es un ente neutral o conciliador, sino que es funcional a las clases dominantes y a la sociedad que a ellos beneficia, es por lo tanto un Estado clasista (Engels, s/f).

Junto con lo anterior, el Estado despliega sus mecanismos de coerción (legales y por la fuerza) en la expansión territorial de la sociedad capitalista, a través de lo que Marx (1999) denominó como la acumulación originaria o primitiva. Son procedimientos violentos sustentados por el Estado que tienden a despojar a los productores directos de los medios de producción, mediante el uso de la fuerza por parte de sus aparatos represivos, como en la legitimación de un cuerpo normativo que así lo permite. Ejemplos históricos de ello son el despojo de los campesinos en los países centrales y de los pueblos indígenas en general en las colonias.

\section{Primera mitad del siglo XX: Lenin y Gramsci}

En relación al tema desarrollado en este ensayo, dos intelectuales y políticos marxistas de máxima importancia durante la primera mitad del siglo XX son Lenin y Gramsci. El aporte de ellos respecto la teorización del Estado es de nuestro interés ya que sientan las bases de reflexiones posteriores que emergieron dentro del marxismo y en la antropología. En Lenin tenemos un análisis que se centra en la dimensión represiva/coercitiva del Estado, mientras que con Gramsci - sin negar lo anterior- centra el foco de su análisis en los aspectos ideológicos relacionados a su poder.

El principal escrito de Lenin sobre estas materias es El Estado y la Revolución (Lenin, 1970), libro terminado al cierre de la primera fase de la Revolución Rusa en agosto de 1917 (previo a la toma del poder bolchevique en octubre). Es un documento donde se problematiza teóricamente la cuestión del Estado pensando en una política práctica para la revolución, tanto la que se vive a nivel interno como en Europa Occidental. A su vez, polemiza con corrientes marxistas democrático-burguesas y nacionalistas. Es decir, con quienes, por un lado, niegan la necesidad de una revolución para la construcción del socialismo (sosteniendo exclusivamente la vía electoral) y, por el otro, apoyan a sus Estados (burgueses) en la Primera Guerra Mundial, en vez de impulsar el internacionalismo proletario (v.g. Kautsky).

A partir de una revisión acuciosa de distintos textos de Marx y Engels, Lenin (1970) sostiene el carácter y origen clasista del Estado y su papel como organismo de represión y legitimidad de las clases dominantes sobre las clases subordinadas. 
El Estado es producto y manifestación del carácter irreconciliable de las contradicciones de clase. El Estado surge en el sitio, en el momento y en el grado en que las contradicciones de clase no pueden, objetivamente, conciliarse [...Es el] órgano de dominación de clase, un órgano de opresión de una clase por otra, es la creación del "orden" que legaliza y afianza esta opresión (Lenin, 1970, p. 7).

El autor pone énfasis en la dimensión violenta del Estado buscando justificar teóricamente la política práctica que se debiera seguir para superar el capitalismo. Concluye que, considerando la naturaleza clasista del Estado y de los mecanismos coercitivos que ejecuta para sostener, reproducir y legitimar la dominación entre clases, la única manera en que las clases oprimidas pueden controlarlo para destruir su carácter burgués, es a través de una revolución. La abolición del Estado solo podrá ser posible cuando no existan las clases sociales y las relaciones de explotación económica. Es por ello que el proceso combina los mecanismos políticos revolucionarios con la construcción de bases económicas que lo hagan posible.

Finalmente, critica tanto a quienes cuestionan la posibilidad de una destrucción relativamente rápida del Estado burgués (marxistas gradualistas), como a quienes proponen la destrucción inmediata de toda la estructura del Estado (anarquistas). Para Lenin (1970), la toma revolucionaria del Estado implica la destrucción de su carácter burgués y la constitución de un Estado proletario que usa su fuerza para construir la nueva sociedad. Empero, no es posible suprimir de modo inmediato la estructura estatal sin antes sentar las bases económicas que lo harían posible.

Asumiendo el carácter clasista del Estado y sin negar la dimensión coercitiva enfatizada por Lenin (1970), Gramsci (2006) sostiene que el Estado y su acción no debe buscarse exclusivamente en las instituciones propiamente estatales, como son su burocracia, las fuerzas armadas y policiales, la escuela pública, entre otros. Sino que junto con ellos, el Estado se expresa, a la vez que reproduce a la sociedad de clases mediante una serie de instituciones y organizaciones formalmente privadas o de la sociedad civil, pero que en el fondo son parte del Estado.

Imbricada a esta reflexión, señala que el Estado no opera solo a partir de la fuerza (o la posibilidad de la misma), para dominar a las clases subalternas, sino que también a través sistemas de ideas que legitiman y dan sentido a los diversos actores, y a la sociedad toda, respecto el orden social existente. Es en torno a estos aspectos que se usa el concepto de hegemonía (de extendido uso posterior, como revisaremos ). En la elaboración y reproducción de estos sistemas de ideas hegemónicos, los organismos estatales de la sociedad civil juegan un papel central. Junto con las instituciones formalmente estatales que cumplen funciones positivas (v.g. escuela pública) y negativas/ represivas (v.g. tribunales y cárcel), en la producción y reproducción de las ideas que sostienen valóricamente el sistema dominante, existe una red de organizaciones e instituciones que, en conjunto a lo anterior, configuran la cultura legitimadora del orden actual (asociaciones políticas, sindicales, gremiales, iglesia, la prensa, entre otros). Además del Estado formal, existen "muchas otras iniciativas y actividades pretendidamente privadas que forman [igualmente] el aparato de la hegemonía política y cultural de las clases dominantes" (Gramsci, 2006, p. 151). 
Estas ideologías articulan (imponen) cierto consenso valórico, tanto de dominantes como dominados. Se configura en los últimos cierta "voluntad de conformismo" con la sociedad y su condición de opresión (Gramsci, 2006, p. 152). Sin embargo, este proceso no está exento de lucha y disputa en las distintas instituciones del Estado, tanto políticas-gubernamentales, como de la sociedad civil.

Para Gramsci, "por 'Estado' debe entenderse no solo el aparato gubernamental sino también el aparato 'privado' de 'hegemonía' o sociedad civil” (Gramsci, 2006, p. 153). Es por ello que, "en este sentido se podría decir que el Estado es igual a la sociedad política más la sociedad civil, es decir, la hegemonía reforzada por la coerción" (Gramsci, 2006, p. 155).

En lo que respecta a la proyección política de estas reflexiones, se desprende que todos los campos estatales -gubernamentales y de la sociedad civil- $y$, específicamente los sistemas de ideas que sostienen una situación de dominación, son terrenos constantes de la lucha de clases.

\section{Segunda mitad del siglo XX: marxismo estructural}

Dentro de las interpretaciones del marxismo desarrolladas durante la segunda mitad del siglo $X X$, una de las influyentes (y criticadas), fue el marxismo estructural. Fue nominado de esta forma ya que su principal preocupación es analizar el funcionamiento de las estructuras sociales (económicas, políticas e ideológicas), sus relaciones y contradicciones, sin tener en consideración prioritaria al sujeto (prácticas y sentidos) como agente de la reproducción y cambio social (Pérez, 2008). Tres autores vinculados a esta aproximación son Althusser, Poulantzas y Laclau.

Uno de sus ámbitos de interés ha sido lo político en general, pero especialmente el rol del Estado y su relación con los campos económicos e ideológicos, abordando su funcionamiento en general y en el capitalismo en particular. Se observa un claro enlace con los planteamientos de Lenin y Gramsci, vistos en la sección anterior. Tanto Althusser, Poulantzas y Laclau, con sus especificidades, examinan al Estado como una institución que es simultáneamente coercitiva y articuladora de sistemas de ideas que buscan legitimar y reproducir el orden dominante.

Althusser (2008) plantea que todo modo de producción y su formación social concreta, al mismo tiempo que produce bienes y servicios, debe reproducir a las fuerzas productivas (medios de producción y fuerza de trabajo) y a las relaciones sociales de producción. La reproducción de la fuerza de trabajo y de las relaciones sociales de producción implica no solo aspectos materiales y técnicos, sino que "al mismo tiempo, la reproducción de su sumisión a las reglas del orden establecido, es decir una reproducción de su sumisión a la ideología dominante por parte de los agentes de la explotación y la represión" (Althusser, 2008, p. 119): la burguesía y el Estado.

Comienza destacando al Estado como fuerza represiva y disciplinadora que está al servicio de la clase dominante, lo cual es su "función fundamental" (Althusser, 2008, p. 122). Este debe ser el punto de partida de la teoría marxista del Estado, sin embargo, para avanzar de este nivel teórico descriptivo, profundiza en las insti- 
tuciones que no son formalmente del Estado pero que sí son parte de él ya que cumplen funciones de reproducción ideológica ${ }^{3}$. De esta manera, toda teoría y análisis del Estado, junto con la distinción entre poder de Estado (conservación o toma del poder estatal) y los aparatos represivos del Estado, debe considerar a los aparatos ideológicos de Estado.

Los aparatos represivos de Estado son el gobierno, la administración, el ejército, la policía, los tribunales, las prisiones, y toda institución que opera a través de la fuerza y o la posibilidad del uso de ella. Por su parte, los aparatos ideológicos de Estado implican la producción, transmisión, internalización y reproducción de los sistemas simbólicos funcionales a las clases dominantes. Implican una pluralidad de organizaciones e instituciones, donde gran parte de ellas no son formalmente parte del Estado, pero cumplen un papel central en la construcción de hegemonía. Tendríamos, de esta manera, aparatos ideológicos de Estado de tipo religioso, educacional, políticos (partidos), sindicales, de información (medios), culturales (artes, deportes y literatura), familiar (posee múltiples funciones) y jurídico (el derecho es parte tanto de los aparatos represivos y de los aparatos ideológicos de Estado).

Si la unidad de los aparatos represivos está en su capacidad coercitiva y en su pertenencia formal al Estado, la unidad de la pluralidad de los aparatos ideológicos está en los sistemas de ideas. Tanto los aparatos represivos como los ideológicos son aspectos de la totalidad estatal y operan articulados: "ninguna clase puede tener en sus manos el poder de Estado en forma duradera sin ejercer al mismo tiempo su hegemonía sobre y en los Aparatos Ideológicos de Estado. [...estos] pueden no solo ser objeto sino también lugar de la lucha de clases" (Althusser, 2008, p. 128).

Althusser se propone la elaboración de una teoría general del Estado y de una teoría general de la ideología. Busca caracterizar teóricamente sus aspectos y funcionamientos más allá de las especificidades que pueden adquirir en algún modo de producción particular. En general, se concibe a la ideología como el "sistema de ideas, de representaciones, que domina el espíritu de un hombre o un grupo social" (Althusser, 2008, p. 136). Plantea que las ideologías (en plural) tienen historia propia determinada en última instancia por la lucha de clases, mientras que la ideología en general es a-histórica u omnihistórica en cuanto tiene estructura y funcionamiento propio, inmutable más allá del contenido. Para el autor, los aspectos básicos de la ideología en general son, en primer lugar, que esta representa la relación imaginaria de los individuos con sus condiciones reales de existencia, segundo, que la ideología tiene una existencia material expresada en sus aparatos y su ejecución, al igual que en los actos prácticos de los sujetos, y en tercer término, que "la ideología solo existe por el sujeto y para los sujetos. [...] sólo existe ideología para los sujetos concretos y esta destinación de la ideología es posible solamente por el sujeto: es decir por la categoría de sujeto y su funcionamiento" (Althusser, 2008, p. 144).

Poulantzas (1979), en su última obra Estado, poder y socialismo, diferenciándose de Althusser (2008), no usa la conceptualización de Marx (2008) que distingue entre base o estructura económica y la superestructura político-ideológica ${ }^{4}$. Para él, el uso de esta tipología tiene el riesgo de suponer la existencia de dominios autónomos, que aunque relacionados, operan 
con sus propias reglas, ajenos a las dinámicas de otros campos sociales y del cambio histórico. Asumiendo la preponderancia en última instancia de la esfera económica, lo político y lo ideológico ha estado, aunque de distinto modo, siempre presente -constituyendo y siendo constituido- por lo económico, y viceversa. Hay presencia de las relaciones políticas e ideológicas en el seno de las relaciones de producción, puesto que estas se traducen en poderes de clase, los cuales están articulados a relaciones políticas e ideológicas que los consagran y legitiman; no es una relación de exterioridad/temporalidad de afectación posterior, sino que están presentes desde su constitución. Las relaciones de explotación son a la vez procesos de reproducción de la dominación y subordinación político-ideológica, como también, de lucha de clases.

Las relaciones de producción, de explotación y de extracción del plustrabajo [...], no ha[n] constituido nunca, ni en los otros modos de producción (precapitalistas), ni en el capitalismo, un nivel hermético y cerrado, autorreproducible y en posesión de sus propias "leyes" de funcionamiento interno. Lo político-estatal (y lo mismo sucede en el caso de la ideología) estuvo siempre, aunque bajo formas diversas, constitutivamente presente en las relaciones de producción y, por consiguiente, en su reproducción. (Poulantzas, 1979, p. 12).

Igualmente, Poulantzas (1979) es enfático al señalar que no se puede teorizar ni la economía, ni el Estado, ni la ideología, de forma abstracta y a-histórica. Si bien pueden existir principios generales, como los formulados por Marx (2008) para la economía, la teorización precisa debe corresponder siempre a su forma en cada modo de producción y sus variaciones. Es por ello que el propósito de este autor en este libro es contribuir a la teoría del Estado en el modo de producción capitalista.
La principal tesis que sostiene Poulantzas (1979) es que en el capitalismo, la agudización de la separación entre los medios de producción y los productores directos (llegando en lo general a su disociación plena) da lugar a una "separación relativa" del espacio económico (producción y acumulación) con la esfera Estatal. Esta es la forma específica del Estado en el capitalismo, condición que lo recorre con transformaciones- en sus distintos ciclos y fases. La teorización no puede separarse de las transformaciones del objeto a lo largo del capitalismo en el marco de las dinámicas de luchas de clases específicas. Por lo tanto, la teoría del Estado capitalista debe poder abordar las distintas "formas del Estado según los estadios y fases del capitalismo (Estado liberal, Estado intervencionista etc.), distinción de estas formas y de las formas del Estado de excepción (fascismos, dictaduras militares, bonapartimos), formas de régimen en los diversos países concretos" (Poulantzas, 1979, p. 23).

En lo que respecta al Estado capitalista, Poulantzas (1979) concuerda en que este no se limita a la represión, sino que tiene un papel clave en la producción, organización y reproducción de las relaciones de dominación y de la ideología hegemónica (a través de instituciones formalmente e informalmente estatales), sin embargo, la dinámica estatal no se circunscribe al binomio represión e ideología que vimos con Althusser (2008). La distinción entre aparatos de represión y aparatos ideológicos de Estado es útil con fines descriptivos, sin embargo, sigue asumiendo solo una acción "negativa" del Estado a través de la represión o subordinación ideológica. Sin embargo, las complejidades del poder estatal y su acción práctica y material, nos muestra como en muchísimas ocasiones impulsa acciones "positivas" sobre 
las clases subalternas (en beneficio de ellas). Expresando de esta manera una dimensión material de la dominación, generando consenso y lealtad -hegemonías de clase-, incluso si estas medidas son concesiones impuestas por la lucha de clases. Estas reflexiones están orientadas a explicar las peculiaridades del Estado capitalista de las democracias liberales, bajo sus formas más o menos benefactoras. Es así que, además de los aparatos represivos e ideológicos, debemos considerar los aparatos económicos de Estado.

Junto con lo anterior, se plantea que no todo poder se reduce a lo estatal. Los procesos económicos y las relaciones de clase se configuran en redes de dominación y resistencia que desbordan al Estado, aunque este conserve un lugar protagónico (primacía). Además de ello, nos señala que existen relaciones de poder y luchas que desbordan a las clases sociales, lo cual quiere decir que su fundamento no está en la división social del trabajo (en la explotación económica), sino en otras relaciones de dominación que se dan en el capitalismo. Lo cual no implica que estén al margen de las clases sociales.

La división en clases no es el terreno exhaustivo de constitución de todo poder, aunque en las sociedades de clase todo poder revista una significación de clase. [...] Pero incluso si esas relaciones de poder desbordan a las relaciones de clase [...] los aparatos del Estado no se mantienen al margen de ellas [...] a fin de asignarles una pertinencia de clase y de situarlas en la trama de los poderes de clase (Poulantzas, 1979, p. 45-46).

Laclau (1986), en su teorización respecto al populismo, proporciona elementos adicionales que permiten avanzar en la complejización de lo político y del Estado en el capitalismo.
Relacionado a los últimos temas de Poulantzas (1979), el punto de partida del libro en general y del análisis del populismo en particular, es una crítica a lo que Laclau (1986) llama el "reduccionismo de clases" dentro de la teoría marxista. En la mirada reduccionista, todas "las contradicciones son vistas como un sistema jerárquico que puede ser reducido, directa o indirectamente, a una contradicción de clase. En consecuencia, todo elemento o contradicción a los niveles político e ideológico tiene una pertenencia de clases" (Laclau, 1986, p. 6). De acuerdo al autor, este reduccionismo dificulta la explicación de la variedad histórica de las luchas sociales, de las ideologías burguesas y de las disputas por la hegemonía.

En consideración al tema de este ensayo, no profundizaremos en el análisis del populismo propiamente tal, sino que más bien en las tesis principales que se plantean para el estudio de lo político-ideológico.

Usando los conceptos de base y superestructura de modo ilustrativo, señala que es fundamental distinguir las determinaciones de clases de las superestructuras y las formas de existencia de las clases en ellas. Afirmar la determinación de clase de las superestruc-
turas no significa establecer la forma en que dicha
determinación se ejerce. [Si las clases son] polos de
relaciones de producción antagónicas [...], en cuanto
tales, no tienen ninguna forma de existencia necesaria
a los niveles ideológicos y políticos (Laclau, 1986, pp.
184-185).

El planteamiento central es que el carácter de clase de una ideología no está en su contenido (discurso explícito), sino que en su forma, la cual se revela en su principio de articulación específico, es decir con qué otros componentes 
ideológicos se articula, qué interpelaciones realiza en los sujetos y que acciones políticas conllevan en ellos (sostenedoras o impugnadoras del orden dominante).

La articulación implica y requiere de contenidos no clasistas (ej. Nacionalismo), siendo esta la materia sobre la cual opera -a través de las articulaciones- la práctica ideológica clasista. La ideología dominante interpela a miembros de la misma clase (o bloque) en el poder pero también a los dominados. Esta dominación se concreta en la absorción y neutralización de los contenidos ideológicos en los cuales se puede expresar antagonismo y resistencia a la dominación. La construcción y ejercicio de hegemonía de las clases dominantes implica "eliminar el antagonismo y transformarlo en simple diferencia” (Laclau, 1986, p. 188).

Por otro lado, una fuerza política-social puede articular los contenidos no clasistas, con elementos que interpelen a las clases subalternas a la movilización y configurar una energía de transformación, explicitando la situación de antagonismo y propiciando la resistencia. Es por ello que el discurso propiamente tal no define el carácter de clase de una ideología y movimiento, sino que su principio de articulación y sus consecuencias para la lucha social. "No es en la presencia de determinados contenidos en un discurso, sino en el principio articulatorio que los unifica, donde debemos buscar el carácter de clase de una política y de la ideología" (Laclau, 1986, p. 189).

De lo anterior se desprende que las clases y los grupos sociales (o movimientos e identidades) empíricamente observables en un momento determinado, no tienen por qué coincidir. "Los individuos son los soportes y puntos de entre- cruzamiento de una acumulación de contradicciones, no todas las cuales son de clase" (Laclau, 1986, p. 190). De todas formas, como se indicó, estas contradicciones no clasistas se articulan de distinta forma a ideologías de clase. La clase que logra articular las contradicciones no clasistas con sus intereses e ideologías de clase es la que consigue la hegemonía.

Volviendo al punto de partida, respecto al carácter de clase de las ideologías a partir de las formas de articulación y no del contenido, "es posible afirmar la pertenencia de clase de un movimiento o una ideología y, al mismo tiempo, afirmar el carácter no clasista de algunas de las interpelaciones que constituyen esta última" (Laclau, 1986, p. 191).

Nos parece que de los distintos puntos planteados a lo largo de este acápite respecto el Estado, lo político e ideológico, y sus formas complejas de estructuración y expresión, se desprenden una serie de problemáticas relevantes para una antropología de lo político que se interese en analizar a las clases sociales, la movilización social, el Estado, el poder, las ideologías y las subjetividades.

\section{Estado y marxismo en la antropología}

Si bien desde los preámbulos de la antropología como disciplina existen indicios de estudios sobre las distintas formas de gobierno e instituciones políticas de las "otras" sociedades, el estudio antropológico de "lo político"5 se formaliza a mediados del siglo XX (Balandier, 2005). A lo largo de su desarrollo, la influencia de la teoría marxista sin ser desbordante, tiene cierta presencia. 
Si bien no es posible catalogarlos como marxistas, dos antropólogos pioneros en el estudio de lo político son Balandier (2005) y Gluckman (2009). En ambos casos, no existe una vinculación directa o necesaria del Estado con la división y conflictos de clases sociales. Sin embargo, vale la pena referirlos ya que son antropólogos políticos clásicos que, en momentos donde en la antropología se solía enfatizar en las tendencias al equilibrio de la sociedad y sus estructuras, ellos relevan el conflicto como una cuestión central. Junto con lo anterior, ilustran dos formas de estudio que toman forma posteriormente en la antropología de influencia marxista: una mirada que privilegia el análisis de estructuras y sus componentes (Balandier, 2005) y otra de los procesos, acciones y situaciones (Gluckman, 2009).

\section{El análisis estructural del Estado}

En la antropología marxista (o influenciada por ella), que analiza al Estado y sus dinámicas estructurales, se usan datos etnográficos e históricos para reflexionar sobre el origen y papel del Estado en sociedades pre-capitalistas, en los factores que impulsan la transformación de los sistemas de gobierno (dando origen o no al Estado), y en las relaciones entre los componentes estructurales de la sociedad en sus procesos de cambio 6 .

Uno de los primeros acercamientos en esta línea está en Krader (1972). Se plantea que no existe un origen único del Estado, ya que este órgano surgió en distintos espacios en momentos y condiciones diferentes (por conquista, desarrollo interno de una sociedad o ambas a la vez). A su vez, que no es posible referir a una sola forma de Estado, puesto que cobró existencia, desde sus primeras expresiones hasta la actualidad, en múltiples variantes. No obstante, todos poseen rasgos comunes, definidos por las funciones que cumple en las sociedades donde está presente. Sobre ello, indica que el Estado existe en sociedades de gran población y con presencia de diversas clases sociales, asociaciones y grupos étnicos. Estos conglomerados tienen desigualdades en la distribución de la riqueza y las funciones económicas. El Estado, mediante sus mecanismos, busca la integración social de estas sociedades de carácter heterogéneo y desigual, bajo un poder centralizado.

La integración se realiza mediante mecanismos positivos y negativos. Los positivos se sustentan en fuerzas y emociones sociales como "el amor, la lealtad, la dependencia recíproca, la fe religiosa, la tradición y la fuerza de la costumbre" (Krader, 1972 , p. 23). Tres mecanismos positivos de integración operan hacia adentro de la sociedad. Son la expresión ritual y formal de la unidad de la sociedad (y de esta con el Estado), una ideología donde la sociedad y el Estado se glorifican, y el mantenimiento de la paz interna. A su vez, hay mecanismos de integración positivos que operan hacia afuera, como son la protección de sus límites fronterizos y a través del establecimiento de relaciones extranjeras que aparezcan beneficiosas. Por otro lado, la integración negativa implica mecanismos coercitivos para eliminar las acciones que se visualizan como perturbadoras o rupturistas con ese orden social, como la transgresión de la legalidad y la rebelión. La eficacia de los mecanismos positivos se basa en la concordancia de los órdenes morales de la sociedad y los que promueven y orientan a los agentes del Estado. A mayor disociación, grupos y mayorías de la sociedad se pueden poner en acción contra ese orden social y por ende, ese Estado. 
Friedman (1977), quién parte de un posicionamiento marxista explícito, se preocupa por el cambio social, indagando en el surgimiento del Estado (y otras formas de gobierno) y la transición entre modos de producción. Plantea que el análisis de la reproducción y transformación social no debe disociar el análisis estructural del histórico. Su dinámica depende de las relaciones y contradicciones intersistémicas que se presentan en una formación social en su totalidad?.

Cuestiona el materialismo economicista, señalando que los componentes estructurales no se relacionan mediante vínculos unidireccionales, sino que se transforman entre ellos. Sin embargo, las variantes están determinadas, en última instancia, por la situación y cambio de las condiciones de producción. Estas generan limitantes a "las posibilidades de variación de las relaciones de producción y de toda la estructura social" (Friedman, 1977, p. 234).El modo concreto en que esto acontece será variable históricamente. Él estudia una región y grupo étnico particular (los kachin en Alta Birmania), dando cuenta de cómo el funcionamiento del sistema social en conjunto (condiciones ecológicas, tecnología, relaciones de producción, parentesco, organización social, rituales, religión, entre otros), puede impulsar diferentes formas de transformación en el tiempo. En este caso, dependiendo de la evolución o degradación de las condiciones de producción, las cuales se configuran a partir de la incidencia de distintas partes del sistema social, este puede variar hacia la verticalización mediante la constitución de clases sociales y Estado, o hacia una estructura de clanes acéfalos.

Krader y Rossi (1982), a partir de distintos materiales antropológicos e históricos, abordan las características de las sociedades con y sin Estado, y sus formas de gobierno específico. En las sociedades sin Estado, los individuos trabajan exclusivamente para sus familias, ellos mismos y para los bienes colectivos del grupo inmediato. No hay un ente externo que le pueda exigir la entrega de trabajo o productos hacia afuera de estas esferas. Por su parte, en la sociedad con Estado, se trabaja o cultiva para otros sin existencia de vínculos recíprocos. A su vez, está dividida entre una elite que concentra el poder, con autoridad estable, funcionarios de dedicación exclusiva, constante y con la capacidad de coacción de la fuerza de trabajo.

Para entender el rol del Estado es fundamental destacar que es una sociedad dividida entre quienes trabajan y quienes no trabajan directamente, como también, entre gobernantes y gobernados. Esto implica un acceso desigual al producto del trabajo social, como también, al poder. Para Krader y Rossi (1982), el Estado solo existe (o emerge) donde se presenta la división entre trabajadores directos y no trabajadores que se apropian de parte del trabajo o producto ajeno. Es el principio organizativo que surge en estas sociedades y asegura la existencia de la sociedad en esos términos mediante distintos mecanismos de control, los cuales a su vez, aseguran la persistencia del propio Estado.

\section{Estado, actores y prácticas}

A continuación revisaremos a antropólogos y antropólogas que poseen una influencia marxista y, estudian el Estado priorizando una mirada en actores, prácticas y situaciones. En términos generales, se observa que el Estado ha dejado de ser un foco de análisis como tal y, 
pasa a ser parte de una dimensión del poder que se estudia en conjunto a sus aspectos prácticos y cotidianos. Igualmente, se ha enfatizado el rol de fuerzas sociales más amplias en estas dinámicas, como el colonialismo, la expansión capitalista, entre otros.

Jean y John Comaroff (1991) asumen una antropología histórica entendida como un análisis de dinámicas económicas, políticos y socio-culturales que imbrican como un todo procesos estructurales, acciones y representaciones, las cuales deben considerar distintas escalas de lo social. De este modo, los casos de estudios expresan procesos más amplios como pueden ser el Estado colonial, pos-colonialismo o el colonialismo interno. Los contextos macro, como la formación estatal, son ineludible para entender el nivel local, sin embargo, las dinámicas micro tienen también un devenir propio donde incluso existen espacios de autonomía respecto lo general. En este sentido, tanto las formas de opresión como las resistencias, se expresan de múltiples formas e incluso se sobreponen. A veces de manera explícita y nítida, mientras que otras, de forma encubierta, cotidiana y de alcance situacional.

Gledhill (2000) cuestiona el etnocentrismo de la teoría y reflexión antropológica, como también, la ausencia de contextos históricos y procesos sociales mayores a lo local que sitúen a los estudios etnográficos y a la propia antropología en redes políticas más amplias. En muchos casos, ha existido una invisibilización de las relaciones coloniales, por ende, de las formas que adquiere el Estado y los efectos que genera, en las poblaciones estudiadas tradicionalmente por la disciplina. A partir de esta crítica, rescata perspectivas como el análisis del sistema mundo de Wallerstein y la Teoría de la Dependencia, ya que su internalización en la antropología permitió visibilizar cómo dinámicas globales de economía-política se expresan en espacios locales. No obstante, hace una crítica a los estudios de este tipo que se expresaron en interpretaciones unidireccionales desde lo general a lo local.

Gledhill (2000) propone una antropología histórica atenta a los contextos, que imbrique procesos sociales de distintos niveles, sin omitir las relaciones económicas, políticas y simbólicas macro, pero que a su vez, no reduzca lo local a lo general. Estas interrelaciones y dinámicas de transformación se expresan de múltiples formas y a través de distintas dimensiones, de este modo, la antropología política que promueve debe abocarse a dar cuenta de relaciones de poder y sus formas de representación en distintas sociedades (incluidas la propia) y en diversas esferas de acción social. Así, el Estado, debe ser un ente analizado dentro de un conjunto mayor de aspectos generales y locales que configuran lo político. Más que una antropología del Estado, su propuesta es sobre una antropología de lo político que lo incluya, integrando dinámicas de dominación y resistencia que consideren lo cotidiano y lo estructural.

Por su parte, Crehan (2004) propone una conceptualización que asume la cultura inexorablemente vinculada a la noción de clases sociales, entendiendo a la primera como el modo en que se viven o experimentan las realidades de clase, en cuanto prácticas, percepciones, identidades y relaciones de poder. No existe un esquema predefinido que permita establecer de antemano cómo se expresan en un momento histórico concreto, cuestionando la dicotomía base/superestructura, de ahí la importancia de la investigación y el trabajo etnográfico. Los 
procesos que analiza la antropología a escala etnográfica están inmersos en realidades más amplias que sin lugar a duda inciden en sus configuraciones, de igual forma, la escala micro puede estar incidiendo en cambios o ajustes de los niveles más amplios; el cómo de estos procesos es la pregunta que solo puede responderse adentrándose en esas realidades. Para analizar el poder en determinado espacio es necesario conocer las redes económicas y políticas generales (como el Estado) y a su vez cómo los sujetos viven y denotan esos flujos en su propio espacio, y la manera que inciden en las trenzas de poder local.

\section{Aproximaciones sobre y desde Latinoamérica}

Para finalizar este ensayo, revisaremos algunas propuestas sobre/desde América Latina respecto lo político y el Estado en la región, influenciadas por la teoría marxista. En este caso también distinguimos dos grandes aproximaciones, por un lado, aquellas que priorizan una mirada estructural centrada en la naturaleza, conformación y funcionamiento del Estado Latinoamericano, y, por el otro lado, aproximaciones que apuntan hacia el actor, sus prácticas cotidianas y sistemas simbólicos.

En el primer tipo de aproximaciones referiremos escritos que reflexionan sobre la conformación del Estado-nación latinoamericano en relación a la presencia, reconocimiento y participación de los pueblos indígenas en estas conformaciones estatales. A su vez, relacionan estas temáticas con las dinámicas políticas contemporáneas en el sentido que es una cuestión central para todo proyecto político (partidario, de movimientos sociales, intelectual, etc.) que se sitúe desde la transformación de las relaciones de dominación y explotación existentes en la región.

Díaz-Polanco (2005) circunscribe sus reflexiones dentro de los debates por la autonomía, la autodeterminación, la plurinacionalidad y el multiculturalismo respecto la conformación de los Estados de la región, que se han presentado en América Latina por los levantamientos y movilizaciones indígenas durante las últimas décadas. Expone los desafíos que lo anterior presenta para la configuración y ejercicio de los Estados del continente. Es en este contexto donde para profundizar la democracia, el reconocimiento efectivo (con poder), critica las corrientes político-ideológicas del liberalismo conservador que se opone a este proyecto, y también al relativismo absoluto (responsable de esencialismos etnicistas), desde donde se pronuncian a una autonomía aislacionista. Tanto el liberalismo extremo y el relativismo extremo forman dos aspectos de una misma unidad. Se producen y refuerzan uno al otro.

El autor señala que los desafíos para el marxismo y movimientos progresistas es superar el economicismo e integrar estas problemáticas como parte estructurante de sus análisis y propuestas políticas. Todo proyecto y proceso de transformación del Estado, debe combinar la lucha por la redistribución (clases) con la lucha contra la dominación cultural y el reconocimiento. Aquí se critica al multiculturalismo liberal, donde los problemas de discriminación y exclusión cultural han desplazado los problemas de la desigualdad socioeconómicas. "El punto es, y siempre ha sido, cómo lograr reconocimiento e impulsar la igualdad simultáneamente, como partes del mismo proceso" (Díaz-Polanco, 2005, p. 61). 
González Casanova (2006; 2009) también efectúa reflexiones con una alta orientación para la práctica política. El foco de su análisis es cómo en los países latinoamericanos se constituyen condiciones de neocolonialismo que se caracterizan por la existencia de un colonialismo interno, esto es del bloque en el poder (clases sociales y grupos culturales), que domina y subordina no solo desde lo económico sino también desde lo cultural. Esta situación no solo ocurre con los gobiernos conservadores, sino que gobiernos de izquierda controlados por corrientes reduccionistas de clase o economicistas, también lo ponen en práctica. Desde la izquierda.

Casi todos los líderes e ideólogos dieron prioridad a la lucha contra el imperialismo y a la lucha de clases como base para rechazar la lucha de las etnias, sin que estas pudieran romper las barreras epistemológicas y tácticas que llevaban a desconocer sus especificidades. Así, el problema del colonialismo interno se expresó de manera fragmentaria y dispersa en el pensamiento marxista y revolucionario (González Casanova, 2006, p. 415).

Las relaciones capitalistas, la explotación, operan también dentro de los propios pueblos indígenas, entre algunos de sus integrantes para beneficio de colonizadores o elites neocoloniales. Esto es indígenas dominados por indígenas para beneficio propio y de terceros. A su vez, entre clases subalternas, la condición india es factor de diferencia y discriminación; lo cual dificulta la acción política unificada. Es por ello que la lucha por la autonomía indígena está imbricada con la lucha de clases y de los Estados que buscan romper posición subordinada en la división internacional del trabajo, y de la profundización democrática. Debe existir una articulación de las luchas, en caso contrario, no se transformarán las condiciones que son causa de las desigualdades (González Casanova, 2009).

En los estudios para Latinoamérica referentes a las dimensiones cotidianas del el Estado, existe un debate respecto al concepto de hegemonía. Sin entrar en su detalle, para todos, la hegemonía no implica exclusivamente consenso o dominación ideológica; se comprende como un proceso de lucha por los significados que implica aspectos prácticos y materiales. En su conformación, son centrales los contextos históricos, espaciales y socioculturales que le da forma concreta a las dinámicas de la hegemonía.

Además de lo anterior, no poseen solo una aproximación hacia la cotidianidad de lo político, sino que ha existido una profundización de estas perspectivas avanzando a dar cuenta de aspectos cotidianos en la formación de los Estados como tal. Los grupos subalternos con sus prácticas y significaciones, de resistencia cotidiana y formal (pero invisibilizada), producen también al Estado. De igual modo, se problematiza respecto las complejidades y contradicciones ideológicas y prácticas de los proyectos de las clases dominantes respecto el Estado y la sociedad en general. En este sentido, el Estado no es solo una estructura que se impone y funciona, sino que se está constantemente reproduciendo y transformando en función de prácticas de grupos dominantes y dominados.

Mallon (2003), a partir del análisis del rol del campesinado en conflictos nacionales e internacionales en dos Estados republicanos en formación en el siglo XIX (México y Perú), cuestiona la noción de que el nacionalismo es exclusivamente un fenómeno burgués. En los casos estudiados emerge un nacionalismo campesino 
que se configura a partir de las concepciones y prácticas que ellos van desarrollando en los conflictos. Tienen una participación activa, material e intelectualmente, en la formación del Estado, que está en permanente negociación y disputa con los proyectos y prácticas de otros grupos y clases del Estado en gestación (tanto subalternos como dominantes). La concepción de un Estado-nación unitario y homogéneo es un fenómeno posterior, cuando determinadas elites logran el control del grueso del poder estatal y consiguen que se acepte (por unos) y se imponga (a otros) esta visión.

Roseberry (2002) propone que el concepto de hegemonía no se utilice para entender los momentos de consenso ideológico, sino más bien los procesos de lucha. De este modo, la hegemonía no da forma a una ideología común, sino más bien "un marco material y significativo para vivir a través de órdenes sociales caracterizados por la dominación, hablar de ellos y actuar sobre ellos" (Roseberry, 2002, p. 220). Respecto el Estado, se sostiene que los grupos subalternos, en sus relaciones y disputas entre ellos y con las elites, producen y transforman al Estado como institución y sus prácticas.

Para finalizar, Sayer (2002) critica las grandes abstracciones teóricas sobre el Estado, las que considera una proyección del propio proyecto estatal al darle una unidad y coherencia que no existe en las prácticas concretas del ejercicio de su dominación. Del mismo modo que es una ficción la existencia del Estado como una totalidad homogénea y cohesionada, lo es la existencia de una "cultura popular" como espacio regular y congruente de resistencias. Junto con ello, plantea que, a pesar de la existencia de episodios periódicos de resistencia a situaciones de opresión, la domina- ción es una realidad gran parte del tiempo. En ello es fundamental la hegemonía. La cual concibe no solo como imposición, consenso y disputa, sino que también implica -sin negar la coerción- cierta "complicidad consciente [...]. Es el cinismo, no la incorporación ideológica, la que hace que este sistema funcione" (Sayer, 2002, pp. 234-235). Ocurre por diversas cuestiones, entre ellas, porque las acciones del Estado, a la vez que oprimen, también otorgan poder a ciertas fracciones de los grupos subalternos, lo cual no siempre es parte del proyecto original. El desenvolvimiento del poder estatal y las resistencias son procesos contradictorios y entrelazados.

\section{Reflexiones finales}

Luego recorrer la conexión entre marxismo, Estado y antropología, encontramos distintos puntos de convergencia y diferencia. Desde Lenin y Gramsci se abren dos líneas complementarias de reflexión: por un lado, el Estado desde un ángulo estructural con mayor foco en la coerción explícita, y por el otro, en las distintas cuestiones relativas a los sistemas simbólicos y cotidianos fundidos con el Estado, su dominación y resistencias. Lo que nos parece claro, es que una reflexión que se proponga la acción política, no puede prescindir de ninguno de estos aspectos.

Retornando al presente en Chile, de las acciones represivas y generalizadas del Estado para aplacar la protesta social (con violaciones a los derechos humanos), llama la atención que sea el principal dispositivo usado. Vimos como todo orden desigual se sustenta en la coerción, pero que se haya constituido en el principal instrumento, expresa la fragilidad ideológica del 
neoliberalismo chileno para sostenerse en un contexto democrático. Ya no existe una disputa hegemónica más o menos equivalente, sino que el neoliberalismo ha perdido legitimidad en parte mayoritaria de la población. La acción represiva como se ha expresado, solo ha agudizado esta situación, en vez de contrarrestarla. Las acciones discursivas para oponerse a la movilización, como las estrategias del miedo al caos, la violencia, salto al vacío por proceso constitucional, crisis económica, etc., no han articulado referentes simbólicos aceptados por la ciudadanía, aunque debe reconocerse que han servido para aglutinar a los actores políticos y sociales (minoritarios) que defienden el orden neoliberal.

La pérdida de hegemonía del neoliberalismo no ha sido de un día para otro, aunque así se nos presentó como fenómeno de escala nacional, sino que se sustenta en un malestar acumulado por décadas a partir de las condiciones materiales de existencia, marcadas por la desigualdad y precariedad de la vida ${ }^{8}$.

Por otro lado, la paulatina pérdida de legitimidad del neoliberalismo no se acompañó de un proceso de construcción político e ideológica que se le opusiera como proyecto político general. Es por ello que, una de las características de la rebelión chilena es una floreciente producción de símbolos, prácticas y actores que pudieran dotar de sentido "hacia adelante", a la movilización social. Estos son nítidamente políticos, en cuanto implican una disputa de poder, pero sin anclaje partidario. Los ejemplos son múltiples y ameritan un tratamiento detallado, pero van desde la creación de héroes populares, la destrucción de monumentos y esculturas que representan determinados poderes, la producción material del espacio público con sinfines de rayados, pinturas, murales e intervenciones, cambio de nombre de calles y plazas, entre otros ${ }^{9}$.

Para finalizar, es importante reiterar que las perspectivas planteadas en este ensayo tienen vigencia en el momento actual. Evidentemente, no se trata de tomar los postulados y aplicarlos como dogma, sino más bien, usarlos críticamente y de modo criterioso como referentes para comprender y actuar en las luchas del presente.

\section{Agradecimientos}

A CONICYT-PFCHA/Doctorado Nacional 2019 - folio 21190475 por financiar mis estudios de doctorado. También a Marina Weinberg, quien orientó la selección bibliográfica para la elaboración de una primera versión de este ensayo. Y finalmente, al revisor/a anónimo/a por sus valiosas sugerencias. 


\section{Notas}

${ }^{1}$ Una revisión general sobre el neoliberalismo en Harvey (2007). Sobre Latinoamérica consultar la cuantiosa producción de CLACSO en https://www.clacso.org.ar/libreria-latinoamericana/inicio.php.

2 https://ciperchile.cl/2019/12/20/el-nunca-mas-que-nunca-fueanalisis-de-los-cuatro-informes-sobre-derechos-humanos-tras-el18-0/.

${ }_{3}$ Reconoce el papel de Gramsci en las reflexiones que van en esta línea, sin embargo, señala que sus planteamientos no están sistematizados como cuerpo teórico.

${ }^{4}$ Poulantzas desarrolla parte importante de su obra en sintonía con el estructuralismo de Althusser, sin embargo, en el libro que usamos en este ensayo, se aleja de su influencia y cuestiona algunas de sus proposiciones claves (Duhalde, 2008). Para sus planteamientos anteriores se puede revisar, entre otros, Poulantzas(2007).

${ }^{5}$ A grandes rasgos considera sistemas de gobierno, formas de organización social, relaciones de poder, conflictos y resistencias, ritualidades, performances y sistemas de significados relacionados.

${ }^{6}$ Wolf (2001), autor de influencia marxista, hace un análisis de

\section{Referencias bibliográficas}

Althusser, L. (2008). Ideología y Aparatos Ideológicos de Estado. En Zizek, S. (Comp.). Ideología. Un mapa de la cuestión (pp. 115155). Buenos Aires: Fonde de Cultura Económica.

Balandier, G. (2005). Antropología Política. Buenos Aires: Ediciones del Sol.

Comaroff, J. \& Comaroff, J. (1991). Introduction. En Of Revelation and Revolution. Christianity, Colonialism, and Consciousness in South Africa, Tomo I (pp. 1-48). Chicago: The University of Chicago Press.

Crehan, K. (2004). Gramsci, cultura y antropología. Barcelona: Bellaterra.

Engels, F. (s/f). El origen de la familia, la propiedad privada y el Estado. En Marx, K. \& Engels, F. Obras Escogidas (pp.471-613). Moscú: Editorial Progreso.

Friedman, J. (1977). Tribus, estados y transformaciones. En Bloch, M. (Comp.), Análisis marxistas y antropología social (pp. 191-239). Barcelona: Anagrama.

Díaz-Polanco, H. (2005). Los dilemas del pluralismo. En Dávalos, P. (Comp.). Pueblos indígenas, Estado y democracia (pp. 43-66). Buenos Aires: Consejo Latinoamericano de Ciencias Sociales.

Duhalde, S. (2008). Un debate epistemológico sobre el Estado capitalista. La polémica Miliband-Poulantzas. Kairos, 12(21). Recuperado de https://dialnet.unirioja.es/servlet/ articulo?codigo=2667914 [4/3/2020].

Gaudichaud, F. (2015). Las fisuras del neoliberalismo maduro chileno. Buenos Aires: Consejo Latinoamericano de Ciencias Sociales.

Gledhill, J. (2000). El poder y sus disfraces. Perspectivas antropológicas de la política. Barcelona: Ediciones Bellaterra. orientación estructural sobre la relación entre el poder y la cultura, no obstante, no es profundizado en este ensayo debido a que no se específica en el Estado, sino más bien, en las articulaciones entre estas dimensiones en un sentido más general. Esto comprende al Estado, pero las reflexiones y propuestas sobrepasan a esta institución y su papel.

${ }^{7}$ Sigue el esquema clásico del conocido Prólogo (Marx, 2008), reconociendo varios niveles funcionales dentro de una formación social (fuerzas de producción, relaciones sociales de producción y superestructura). Expone un modelo abstracto de las formas de funcionamiento, relación, contradicción y determinación de estos componentes, y como a partir de ello se desarrolla la reproducción y transformación social.

${ }^{8}$ https://www.celag.org/chile-y-la-cronica-de-un-estallidoanunciado/.

${ }^{9} \mathrm{http}: / /$ www.laizquierdadiario.cl/Patrimonio-y-Memoria-otrofrente-del-estallido-social. https://mundo.sputniknews.com/americalatina/201912161089664049-los-heroes-del-estallido-social-en-chile/.

Gluckman, M. (2009). Costumbre y conflicto en África. Lima: Asociación Civil Universidad de Ciencias y Humanidades.

González, P. (2006). Colonialismo interno [una redefinición]. En Borón, A; Amaedo, J. \& González, S. (Comp.). La Teoría Marxista Hoy. Problemas y perspectivas (pp. 409-434). Buenos Aires: Consejo Latinoamericano de Ciencias Sociales. (2009). Las etnias coloniales y el Estado multiétnico. En González, P. De la sociología del poder a la sociología de la explotación: pensar América Latina en el siglo XXI (pp. 293-309). Bogotá: Siglo del Hombre Editores/Consejo Latinoamericano de Ciencias Sociales.

Gramsci, A. (2006). Política y Sociedad. Santiago: Editorial Centro Gráfico.

Harvey, D. (2007). Breve historia del Neoliberalismo. Madrid: Akal.

Krader, L. (1972). La formación del Estado. Barcelona: Labor.

Krader, L. \& Rossi, I. (1982). Antropología Política. Barcelona: Anagrama.

Laclau, E. (1986). Política e ideología en la teoría marxista. Capitalismo, fascismo, populismo. Madrid: Siglo XXI.

Lenin, V. (1970). El Estado y la revolución. La doctrina marxista del Estado y las tareas del proletariado en la revolución. Moscú: Editorial Progreso.

Mallon, F. (2003). Historia política desde abajo. Hegemonía, el estado y los discursos nacionalistas. En Mallon,F., Campesinado y Nación. La construcción de México y Perú poscoloniales (pp.77-108). México D.F.: Centro de Investigaciones y Estudios Superiores en Antropología Social/Colegio de San Luis/Colegio de Michoacán. 
Marx, K. \& Engels, F. (1999). Manifiesto del Partido Comunista. Marxist Internet Archive: https://www.marxists.org/espanol/me/1840s/48-manif.htm. [Consulta: 7/9/2017].

Marx, K. (1999). La llamada acumulación originaria. En Marx, K. El Capital Tomo I (pp. 607-649). México D.F.: Fondo de Cultira Económica.

(2008). Contribución a la crítica de la economía política. México D.F: Siglo XXI.

Ouviña, H. \& Thwaites, M. (Comp.). (2018). Estados en disputa: auge y fractura del ciclo de impugnación al neoliberalismo en América Latina. Buenos Aires: El Colectivo.

Pérez, C. (2008). Proposiciones de un marxismo hegeliano. Santiago: Editorial Universidad ARCIS.

Poulantzas, N. (1979). Introducción. En Poulantzas, N., Estado, poder y socialismo (pp. 4-49). Madrid: Siglo XXI.
(2007). Poder político y clases sociales en el Estado capitalista. México D.F.: Siglo XXI.

Roseberry, W. (2002). Hegemonía y lenguaje contencioso. En Joseph, G. \& Nugent, D. (Comp.). Aspectos cotidianos de la formación del Estado. La revolución y la negociación del mando en el México moderno (pp. 213-226). México D.F.: Ediciones Era.

Sayer, D. (2002). Formas cotidianas de formación del estado: algunos comentarios disidentes acerca de la 'hegemonía'. En Joseph, G. \& Nugent, D. (Comp.). Aspectos cotidianos de la formación del Estado. La revolución y la negociación del mando en el México moderno (pp. 227-238). México D.F.: Ediciones Era.

Wolf, E. (2001). Figurar el poder. Ideologías de dominación y crisis. México D.F.: Centro de Investigaciones y Estudios Superiores en Antropología Social. 